\title{
Rare Case of Spindle Cell Carcinoma in Inverted Papilloma
}

\author{
${ }^{1}$ Sanajeet K Singh, ${ }^{2}$ Kamal D Joshi, ${ }^{3}$ Shilpi Saxena
}

\begin{abstract}
Aim: The aim of this case report is to sensitize about the possibility of early malignant transformation in an inverted papilloma (IP) and presence of rare spindle cell carcinoma (SPCC) in IP, which can masquerade as a benign lesion.
\end{abstract}

Background: Inverted papillomas are benign tumors of sinonasal tract with characteristic histological features. Though benign, these lesions show recurrence, are locally aggressive, and have potential for malignant transformation.

Case report: A case of IP is described, which recurred following wide local excision and underwent malignant transformation into aggressive spindle cell variant of squamous cell carcinoma. A 48-year-old male presenting with unilateral nasal obstruction and serosanguinous discharge was detected to have reddishgray nasal mass arising from lateral wall of right nasal cavity. The histopathological examination was suggestive of IP. A medial maxillectomy and excision was done. However, recurrence was detected within 6 months. There was subsequent rapid malignant transformation into SPCC, which is a rare type of squamous cell carcinoma and even rarer in malignant transformation of IP.

Conclusion: The patient was managed promptly with radiotherapy after diagnosis of malignant transformation was made and is under follow-up. The case highlights the importance of follow-up care in IP, as early recurrence can be there. Moreover, malignant transformation, especially rarer type of SPCC, made the case more challenging.

Clinical significance: The diagnosis of SPCC required a high index of suspicion as it is a rare variety of squamous cell carcinoma arising as malignant transformation of IP and mimics many other reactive or mesenchymal lesions.

Keywords: Inverted papilloma, Malignant transformation, Maxillectomy, Spindle cell carcinoma, Squamous cell carcinoma.

How to cite this article: Singh SK, Joshi KD, Saxena S. Rare Case of Spindle Cell Carcinoma in Inverted Papilloma. Int J Otorhinolaryngol Clin 2017;9(2):64-67.

Source of support: Nil

Conflict of interest: None

\footnotetext{
${ }^{1}$ Professor, ${ }^{2,3}$ Graded Specialist

${ }^{1}$ Department of ENT, Army Hospital (R\&R), New Delhi, India

2Department of ENT, Military Hospital, Roorkee, Uttarakhand, India

${ }^{3}$ Department of Pathology, Military Hospital, Roorkee, Uttarakhand India

Corresponding Author: Kamal D Joshi, Graded Specialist Department of ENT, Military Hospital, Roorkee, Uttarakhand India, Phone: +917507088660, e-mail: kdeepjoshi@rediff.com
}

\section{BACKGROUND}

Inverted papilloma is a benign tumor, in which surface epithelial cell grows downward into underlying supportive tissue, without breach of basement membrane. ${ }^{1,2}$ It is locally aggressive, has tendency to recur, and is associated with synchronous or metachronous malignancies.

Various studies mention that it represents 0.5 to $4 \%$ of all primary tumors of sinonasal cavity and has a male preponderance with male:female ratio of $3: 11^{2,3}$ However, male:female ratio of 10:1 has also been mentioned by Saha et al. ${ }^{4}$ The overall incidence of tumor is 0.6 to 1.5 cases $/ 100,000 /$ year. $^{1,2}$

The etiology of IP is unknown; however, the role of allergy, chronic sinusitis, inflammation and occupational exposure has been implicated. Recent research has highlighted the role of viral infection as a possible causative agent. Human papilloma virus (HPV), is linked with causation as well as determining the clinical course. The HPV serotypes 6 and 11 are associated with lower rate of recurrence and malignant transformation as compared with HPV 16 and 18. ${ }^{2,5}$

Clinically, IPs present as reddish-gray livid colored masses, with uneven surface and bleed on touch. Local advance of disease can result in various symptoms like broadening of nose, anosmia, hypo- or hyperesthesia, trismus, dental and visual complaints. The symptoms are usually delayed, as the tumor grows asymptomatically in the sinus cavity. Nasal obstruction, rhinorrhea, and epistaxis are usual presenting complaints.

Biopsy is required for definitive diagnosis; however, open biopsies are avoided to prevent contamination of unaffected tissue planes.

As far as role of imaging is concerned, computed tomography (CT) and magnetic resonance imaging (MRI) are complementary to each other. On CT, IPs have variable and nonspecific appearance; however, it provides superior bony definitions and detects lymph nodes metastasis. Moreover, MRI can accurately determine the extent of lesion, perineural, dural and intracranial extension, with better delineation of tumor. Inverted papillomas have heterogeneous appearance on MRI and a typical cerebriform pattern is detected in 80 to $100 \%$ of cases, focal loss of which can be indication for surgery. ${ }^{2,6}$

Surgery remains the chief modality of treatment. The surgical techniques commonly used are endoscopic 


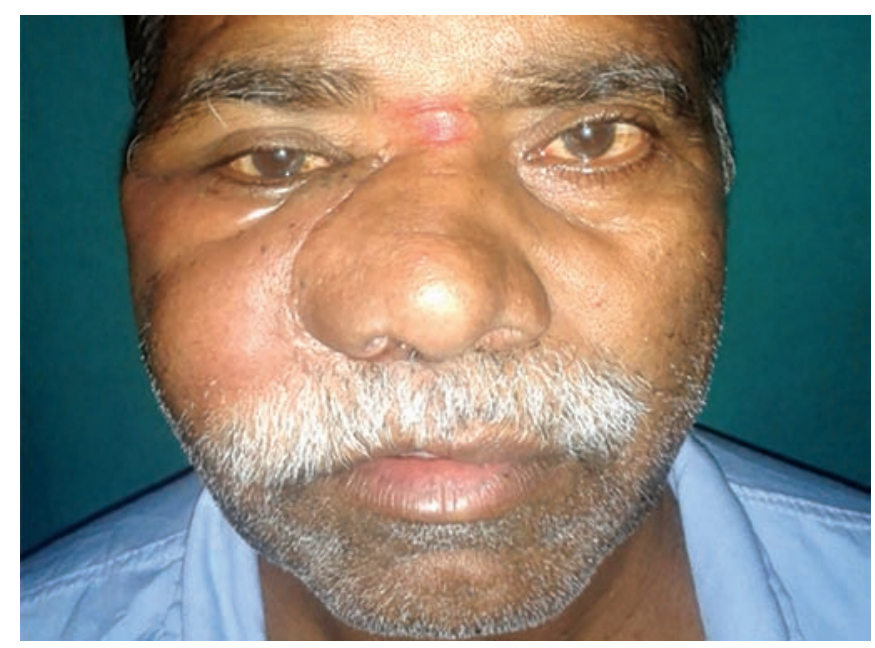

Fig. 1: External nasal deformity in case of malignant transformation of IP

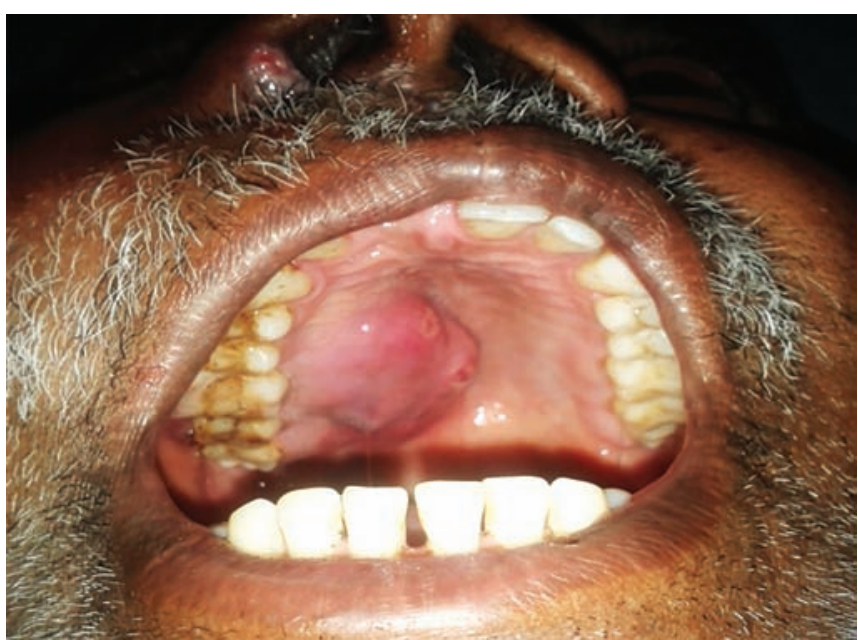

Fig. 2: Inverted papilloma (operated) with malignant transformation; involvement of hard palate approach, lateral rhinotomy, craniofacial resection and mid-face degloving approach. Irrespective of approach, which depends on extent of disease, the aim of surgery is to remove all diseases along with clearance of all margins including adjacent bone surfaces. ${ }^{2,5,7}$

Medical therapy using mitomycin, interferon, and antiviral agent like cedofovir is still under evaluation. Radiotherapy is generally reserved for recurrence, residual tumor, or transformation to malignancy. Malignant transformation due to radiotherapy is a possibility ${ }^{8,9}$; however, few studies refute it. ${ }^{10}$ Indication of radiotherapy in IP is locally advanced aggressive disease, malignant transformation, recurrence or residual disease, unresectability, and patient unwilling or unfit for surgery. ${ }^{11}$

\section{CASE REPORT}

A 48-year-old male presented with complaints of progressive, unilateral obstruction of right nasal cavity, associated with intermittent serosanguinous discharge for 6 months. On examination, a reddish-gray mass with irregular surface arising from lateral wall of right nasal cavity was detected. The mass was not tender and was bleeding to touch. A biopsy of nasal mass was taken and histopathological report was suggestive of IP. Imaging showed mass confined to right maxillary sinus and right nasal cavity.

A medial maxillectomy was done for excision of the IP. During routine follow-up, after 6 months, a recurrence was detected, and histopathological examination confirmed IP. As the patient was asymptomatic, the follow-up visits were irregular and patient was lost to follow-up.

After 10 months, the patient again presented with right-sided nasal obstruction associated with serosanguinous discharge and deformity of nose (Figs 1 and 2).
Contrast-enhanced CT-paranasal sinus and neck (Fig. 3) revealed the lesion extending into subcutaneous plane and involving overlying skin. It was abutting anterior wall of sphenoid superiorly and extending into nasopharynx. Erosion of medial pterygoid plate, floor of the frontal sinus without intracranial extension, and hard palate and maxillary alveolus was also present.

A biopsy was taken again and histopathological examination was suggestive of IP. Following biopsy, the patient underwent total maxillectomy and excision of tumor. Intraoperatively, partial erosion of hard palate and orbital floor was also noted. Histopathological examination of excised mass revealed focus of spindle cell squamous carcinoma in the specimen (Fig. 4). The patient was planned for endoscopic multiple site biopsy, which revealed residual IP in lateral wall of nose and floor of nasal cavity and nasopharynx showed involvement by spindle cell squamous carcinoma. The patient was further managed with postoperative radiotherapy and is under follow-up.

\section{DISCUSSION}

The high recurrence rate of IPs can be attributed to multicentric nature, aggressive nature due to which it invades deep into stroma, or inadequate surgery. Various studies mention recurrence rate ranging from 6 to $75 \%$., $, 4,7$ Recurrence was commonly associated with young age, smoking, extent of origin, frontal sinus origin, absence of inflammatory polyp, hyperkeratosis, squamous epithelial hyperplasia, epithelial atypia, and increased mitotic index.

Review of literature suggests an undeniable link between carcinoma and IPs. The risk of malignant transformation is 10 to $15 \%{ }^{3,7}$; however, rates as high as $50 \%$ have also been reported. The malignancy associated is synchronous or metachronous, with 7 to $8 \%$ and 1 to $3 \%$ 

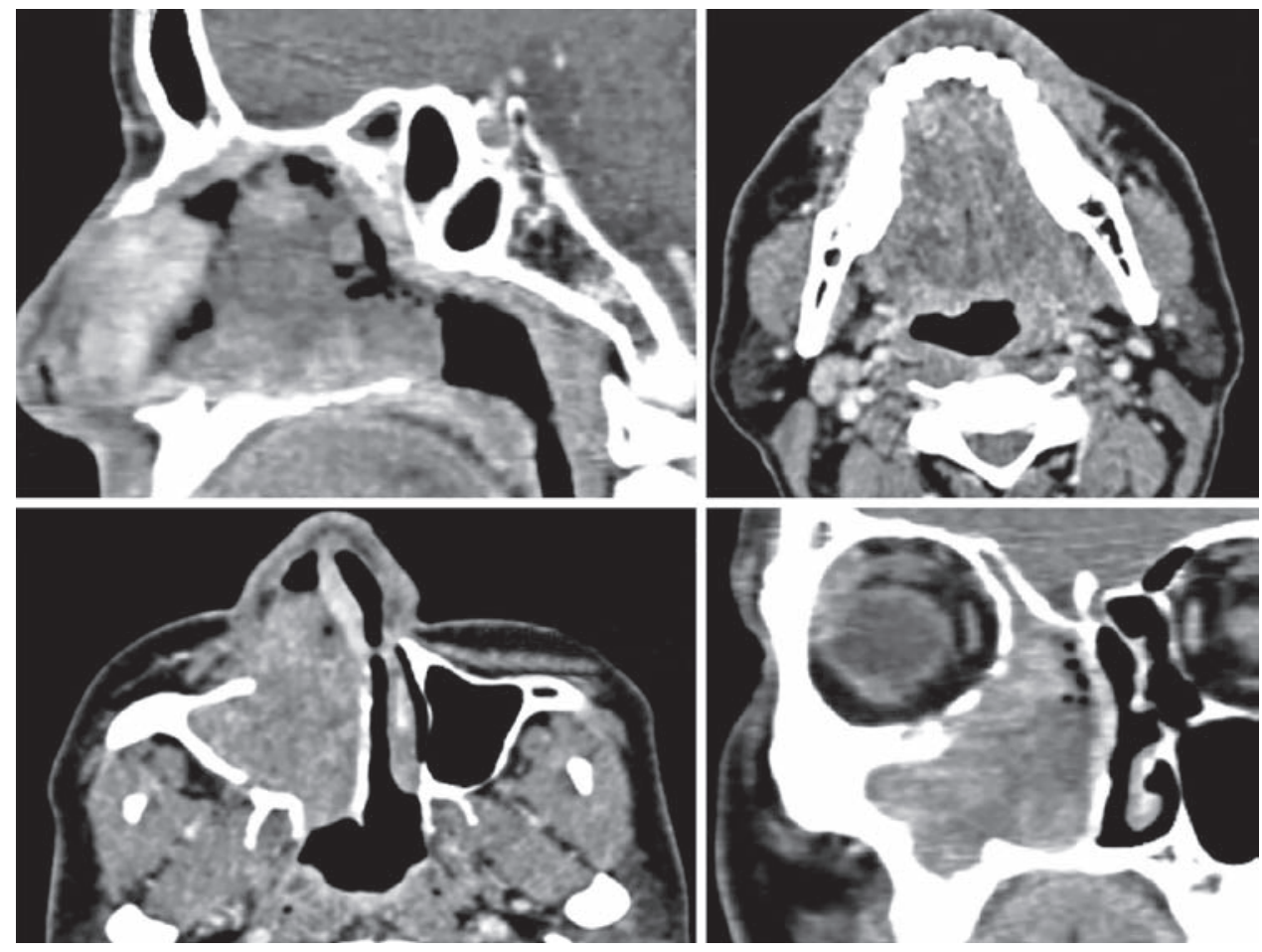

Fig. 3: Contrast-enhanced CT nose and paranasal sinus
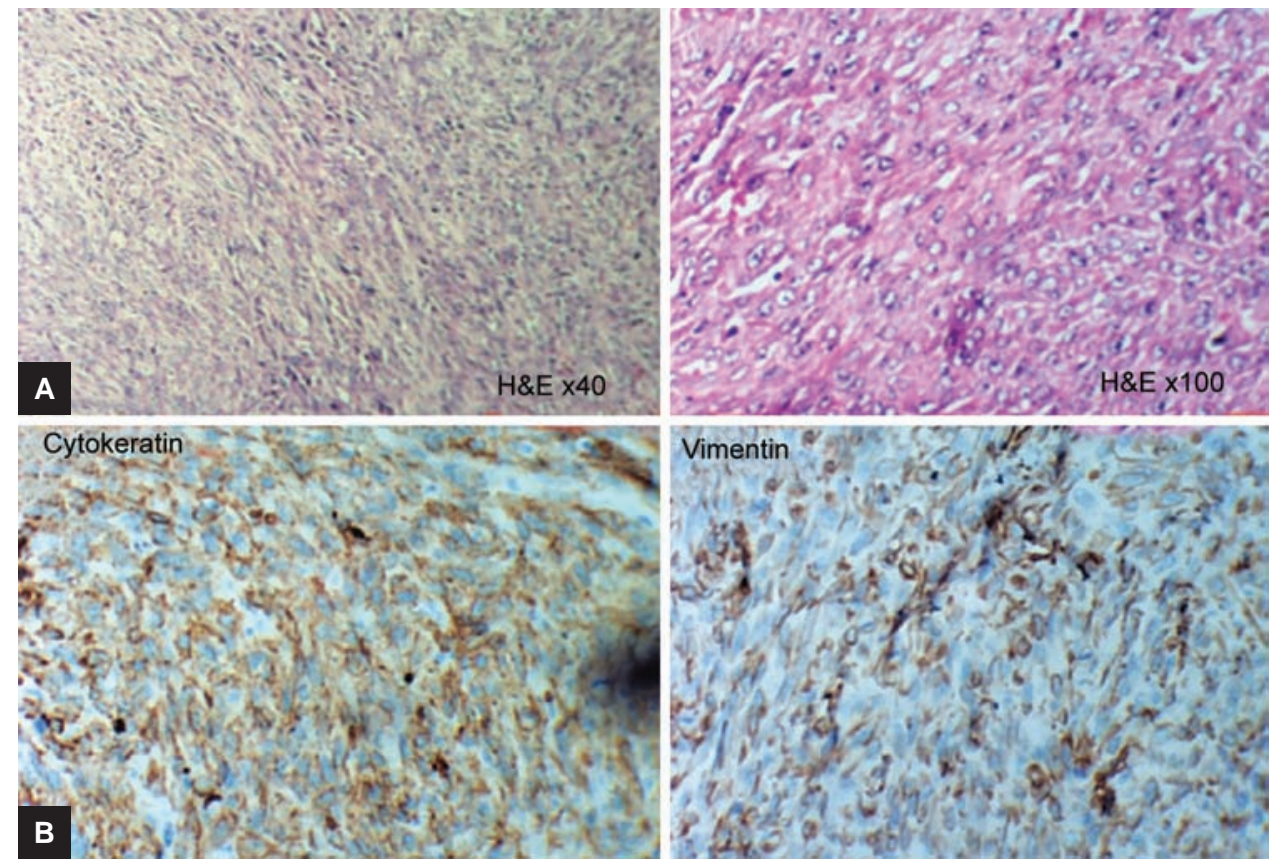

Figs 4A and B: Histopathological examination: (A and B) Hematoxylin-eosin stain with 40x and $100 \times$ magnification. Immunohistochemistry — cytokeratin and vimentin positive

respectively. ${ }^{1}$ Wassef et $\mathrm{al}^{2}$ suggested that bilateral IPs, histological multicentricity, epithelial diversity, severe hyperkeratosis, high mitotic index, absence of inflammatory polyp, increased plasma cells, decreased eosinophil, neutrophil, ratio of neoplastic epithelium:stroma increases, and increased mitotic index are associated with malignant transformation of IPs.

The exact etiology of malignant transformation of IPs is, however, still unknown. Many investigators have implicated the role of HPV, which is classified as type $6 / 11$ as low-risk type group and type 16/18 as high-risk group. ${ }^{2,5}$ The presence of HPV-positive squamous cell carcinoma can have an implication in management, as these have a better prognosis after chemo- and radiotherapy due to intact apoptotic mechanism. The most common malignancy associated is squamous cell carcinoma. ${ }^{3}$ The present case showed malignant transformation of IP into spindle cell squamous carcinoma, which is a subtype/ 
variant of squamous cell carcinoma and has spindle tumor cells, similar to tissues of mesenchymal origin, but are in fact epithelial in nature. Kim et $\mathrm{al}^{12}$ mentioned that very few cases of malignant transformation of IP to SPCC have been reported in literature.

Spindle cell squamous carcinoma is more common in larynx and trachea, and nose represents an uncommon site. Most of SPCC have conventional and spindle cell component, but a large number can have total absence of squamous component. ${ }^{13,14}$ Immunochemistry can distinguish SPCC from mesenchymal tumor. However, at least one epithelial marker is present in only $63 \%$ of cases. Almost $100 \%$ of SPCC are positive for Vimentin-a mesenchymal cell marker.

A high index of suspicion and sound knowledge of clinical course of IPs is instrumental in detecting malignant transformation to SPCC, which could have been diagnosed as reactive lesion or mesenchymal lesion.

\section{CONCLUSION}

Inverted papilloma is a benign epithelial tumor, which is locally aggressive, and has a malignant transformation potential. The patient had an early recurrence and developed locally aggressive disease. The diagnosis of SPCC required a high index of suspicion as it mimics many reactive or mesenchymal lesions.

\section{Clinical Significance}

Though the malignant transformation in an IP is known entity, yet the diagnosis of SPCC required a high index of suspicion as it is a rare variety of squamous cell carcinoma arising as malignant transformation of IP and mimics many other reactive or mesenchymal lesions. The rapid recurrence and malignant transformation within a span of a year make the case more clinically significant.

\section{REFERENCES}

1. Gras-Cabrerizo JR, Montserrat-Gili JR, Olmo AP, de Juan M, Massegur-Solench H. Bilateral inverted papilloma of the paranasal sinus: literature review. Clin Rhinol 2011 Sep-Dec; 4(3):141-144.

2. Wassef SN, Batra PS, Barnett S. Skull base inverted papilloma: a comprehensive review. ISRN Surg 2012 Dec;2012:175903.

3. But-Hadzic J, Jenko K, Poljak M, Kocjan BJ, Gale N, Strojan P. Sinonasal inverted papilloma associated with squamous cell carcinoma. Radiol Oncol 2011 Dec;45(4):267-272.

4. Saha SN, Ghosh A, Sen S, Chandra S, Biswas D. Inverted papilloma: a clinic-pathological dilemma with special reference to recurrence and malignant transformation. Indian J Otolaryngol Head Neck Surg 2010 Oct;62(4):354-359.

5. Kim RK. Inverted papilloma. J Rhinol 2001 Jan;8(1-2):5-10.

6. Jeon TY, Kim HJ, Chung SK, Dhong HJ, Kim HY, Yim YJ, Kim ST, Jeon P, Kim KH. Sinonasal inverted papilloma: value of convoluted cerebriform pattern on MR imaging. AJNR Am J Neuroradiol 2008 Sep;29(8):1556-1560.

7. Iqbal SM, Khan IA, Khan IZ, Malik S. Inverted papilloma of the nose and sinuses: clinical presentation, surgical treatment and outcome. J Surg Pak (Int) 2008 Apr-Jun;13(2):85-87.

8. Woodson GE, Robbins KT, Michaels L. Inverted papilloma. Considerations in treatment. Arch Otolaryngol 1985 Dec;111(12):806-811.

9. Dolgin SR, Zaveri VD, Casiano RR, Maniglia AJ. Different options for treatment of inverting papilloma of the nose and paranasal sinuses: a report of 41 cases. Laryngoscope 1992 Mar;102(3):231-236.

10. Mendenhall WM, Million RR, Cassisi NJ, Pierson KK. Biologically aggressive papilloma of nasal cavity: the role of radiation therapy. Laryngoscope 1985 Mar;95(3):344-347.

11. Jha AK, Goyal A, Sharma S, Upadhyay S, Mishra SC, Sah SP. Inverted papilloma of nose with orbital involvement and malignant transformation. Indian J Otolaryngol Head Neck Surg 2003 Apr;55(2):124-126.

12. Kim BS, Park JH, Park YK, Kim KS. A case of spindle cell carcinoma accompanied by inverted papilloma. Korean J Otolaryngol 2003;46(6):520-523.

13. Gupta S, Santoriello D, Wieczorek R, DeLacure MD. Spindle cell carcinoma of the nasal cavity. Rare Tumors 2013 Feb;5(1):10.

14. Lewis JS Jr. Spindle cell lesion - neoplastic or non neoplastic? Spindle cell carcinoma and other atypical spindle cell lesions of the head and neck. Head Neck Pathol 2008 Jun;2(2):103-110. 